\title{
Understanding of Self: Buddhism and Psychoanalysis
}

\author{
Whachul $\mathrm{Oh}^{1}{ }^{1}$
}

Accepted: 27 September 2021 / Published online: 8 October 2021

(c) The Author(s), under exclusive licence to Springer Science+Business Media, LLC, part of Springer Nature 2021

\begin{abstract}
The healing of the self-or the psychological health of the self-has been an intensely studied issue in the traditions of both Buddhism and psychoanalysis. It is easy to suppose that the understanding of self in Buddhism cannot coexist with the understanding of self in psychoanalysis because the self in Buddhist tradition is mainly regarded as an illusion and needs to be deconstructed, whereas in psychoanalysis, it should be re-constructed for mental health through analysis. Because of this difference in the understanding of self, one may also suppose that these two respective paths to a balanced mind would inevitably be different.
\end{abstract}

Keywords Self $\cdot$ Buddhism $\cdot$ Psychoanalysis $\cdot$ Freud $\cdot$ Kohut

\section{Introduction}

Self, as it is considered in Buddhism and the therapeutic methods used to deal with it, is not only comprehensible from an analytical standpoint, but through addressing analogies and similarities of both traditions as well as by discussing differences, some benefit to psychoanalytic practice may be revealed. To this end, I will first investigate self from the Buddhist and psychoanalytic traditions. Regarding Buddhism, I will focus mainly on the understanding of self in Zen Buddhism and argue that self as a separate entity is an illusion. For the analytic perspective, I will focus on Kohut's understanding of the nature of self, which cannot be separated from object, and compare his view with Descartes and Freud's understanding of self. Next, I will explore therapeutic methods in Buddhism and psychoanalysis. In examining Buddhism, I will not only discuss the basic approach of meditation in general, but also explore Vipassana Meditation as one of the Buddhist meditations that emphasize the meditator's awareness of the present. Concerning psychoanalysis, I will investigate two aspects: Freud's "evenly hovering attention" and Kohut's "empathy." Third, I

Whachul Oh

whachul@gmail.com

1 Seoul Christian University, Seoul, South Korea 
will try to understand self in Buddhism by comparing it with that of psychoanalysis. In this part, I will argue that Zen Buddhism completely overcomes the distinction between self and object because of the self that has the "spirit of inquiries." However, a distinction between self and object still exists for Kohut. I will also argue that the concept of "non-distinction" between self and object can be appreciated from the developmental perspective. Finally, I will address the differences and similarities between the therapeutic methods of each tradition. Vipassana meditation and psychoanalysis are non-judgmental methods created for the purpose of becoming aware of the situations of human beings. The Buddhist practice of non-attachment can complement Freud's "evenly hovering attention." Finally, I will delve into the meditative experience of "emptiness" through psychoanalytic theories.

\section{Self in Buddhism}

From the Buddhist perspective, the idea of "individual self" is an illusion. It is not possible to separate self from its surroundings. Buddha in Lankavatara Sutra states, "Things are not what they seem... Deeds exist, but no doer can be found" (Majjhima Nikaya, 192). Zen Buddhism shows that there is no antithesis of self and "no-self." Paradoxically, the true nature of self becomes known only by inquiring, doubting, and negating self. Suzuki writes, "to exercise yourself properly in Zen you ought to cherish a spirit of inquiry; for according to the strength of your inquiring spirit will be the depth of your enlightenment" $(1952,107)$. With this "spirit of inquiry," Zen devotees doubt and deconstruct the certainty of anything that exists until they have no doubt and arrive at the paradoxical truth where there is neither self nor no-self. As Suzuki writes, "The problem of the self evaporates into sheer abstraction when pursued analytically, leaving nothing behind." He further notes, "It is because of this inquiring mind that the earlier Zen devotees became dissatisfied with all the intellectual explanations of things, and that they came finally to master and knew what they wanted of him" (Suzuki, 1952, 127).

Although Buddhism devotees continuously inquire into and doubt the existence of the individual self, they do not deny the existence of "I," who inquires and doubts self-certainty. For this reason, Buddha introduces the middle way, which is neither a self nor a no-self doctrine. Lankavatara Sutra writes, "The ultimate truth transcends the antithesis of self and not-self" (Suzuki, 1952, 51). As Garfield comments on one Buddhist scripture, "Buddhas have referred to a self, they have taught no-self and they have also taught neither self nor no-self" (Garfield, 6). One great insight Buddhism teaches is the middle way, whose focus is neither self nor no-self but metaself who is an "inquiring spirit."

\section{Cartesian Self and Self in Psychoanalysis}

According to the Cartesian view of modern philosophy, the existence of the self cannot be questioned. In Cartesian philosophy, the subject-as- "I" has the certainty of existing separately from the object-as- "others." In the Cartesian understanding of 
humanity, although other matters are in doubt, there is the certainty of self-identity because the subject can rationally think that he exists (i.e., cogito, ergo sum). This rationally thinking mind cannot be separated from human existence. According to this idea, humans lose their identity if a thinking mind is not established. Only a thinking mind provides the certainty of self-identity. Schermer (2002) affirms this idea: "When we give up mind, as if that is even possible, we are nothing and nowhere. We fear that nothing will be left of us and that we will become total nonentities. We equate our selves and our personal value with our thoughts, our minds" (57). Furthermore, because the self doubts everything except for the existence of "I," self becomes separated from "others." In other words, in Cartesian thinking, there exists a separation between self as "I" and object as "others."

Opposing modern Cartesian philosophy's assertion of the separation between "I" and "others," one of the post-Freudian psychoanalysts-Kohut_-believes that self cannot be separated from object. For him, the modern-day concept of the indubitable "I" that can be separated from "others" is a fallacy. Other people call this "the myth of the isolated mind" (Stolorow \& Atwood, 1992). The thinking of the "I"-asself cannot be separated from others-as-object. Kohut creates the concept of "selfobject" in order to explicate the intimate relationship between self and object. For him, self-object is the object that is "either used in the service of the self and of the maintenance of its instinctual investment, or [are] objects, which are themselves experienced as part of the self" (1971, xiv). In other words, although the "I" uses the others to serve the "me," others are also experienced as part of "I."

Kohut presents self-object by discussing and criticizing Freud's view of the relationship between self and object. For Freud, self is not separated from object in the early stage of human development. At this stage, the relationship of self and object is narcissistic. At a later stage, however, in the case of normal psychological development, self becomes independent from object so that this narcissistic object becomes a love object. Contrasting Freud's idea, that the mature relationship of self and object is the self's independence from object, Kohut insists that the self-object relationship endures throughout the entire human life. Kohut writes, "Self-selfobject relationships are present from birth to death" $(1984,52)$.

Kohut's idea of self is a "new frame of reference" and a "new viewpoint" (Kohut, 1979, 3). In terms of Thomas Khun, this is a paradigm shift. This new viewpoint is not consistent with pre-modern Newtonian science, but rather with modern physics. While Newtonian science separates the observer from the observed, modern physics cannot separate them. Kohut writes, "[modern physics] has taught us that, in principle, the observing agency is always a part of what is being observed, that, again in principle, there is no objective reality" $(1984,36)$. This new viewpoint is also discordant with Freud's Cartesian psychoanalysis, which presupposes the clear distinction between self and object. Kohut criticizes Freud's analysis while applying the insight of modern physics to elucidate the clinical situation, in which the analyst-self is not separable from the patient-object (1984, pp. 34-37).

In the new analytic frame, the thinking "I"-as-subject already includes others-asobject. The self has a constant relationship with the object. This self is intersubjective (Atwood \& Stolorow, 1984), social constructionist (Hoffman, 1991), and interactional (Ehrenberg, 1992). As Schlauch writes about Kohut's self-object, "from the 
point of view of the experiencing self, it is proper to say that self 'includes' selfobject, that is, self is 'in' a self-object relationship" (66). In other words, for Kohut, self is relational (Mitchell, 1988). Since self cannot be separated from self-object, Kohut considers it "the psychological oxygen of life" (1984, 47; 1977, 85, 253). As a result, objects "[are] experienced as part of our self" (Kohut, 1978, 177).

However, for Kohut, there still exists a distinction between self and object. Schlauch explains this distinction: "Self is at once one with yet distinct from, a part of, yet apart from, self-object(s): self is at once connected yet separate. Self is ance unique in each self-object relationship yet identical across all self-object relationships: self is at once multiple yet singular" (Schlauch, 66-67). Although self cannot be separated from objects, there exists a self that coheres in spite of various relationships with a variety of objects. Kohut (1977) considers this self mature, "a cohesive self" (262), although this self is not completely "knowable in its essence" (311). This self is "the content of the mental apparatus" and "the center of the individual's psychological universe" (1977) that endures beyond time and place (Kohut, 1971, xv).

\section{Therapeutic Method}

In Buddhist meditation, any attempt to shape individual identity as self creates suffering. The formation of a cohesive self does not solve the problem of self; rather, the attempt of the formation of the self creates suffering because self is, according to Buddhism, an illusion. One psychoanalyst, Jack Engler, who practices and studies Vipassana Meditation, writes, "[in meditation], the striving for sense gratification and for selfhood, which have been the basis of mental life up to and including the stages of identity and object constancy, are seen as the next potential point of arrest and source of suffering" (Engler, 44). However, the meditators are not required to prohibit gratification; rather, it is recommended that the meditators be carefully aware of their own desires to shape self during meditation in order to deconstruct these desires. The function of "I" that observes the self's pursuit of self-certainty should be strengthened so that self can be clearly detected and finally lose the degree of its desire. Mark Epstein writes, "Buddhist meditation tends to intensify certain ego functions so that the sense of self is at once magnified and deconstructed" (Epstein, 120). For a Buddhist, to meditatively explore the human being's innermost desire for self-certainty and identity is the most important way to overcome human suffering. This exploration in meditation leads to the experience of "emptiness" that "serves to destroy idea of a persisting individual nature" (Guenther, 1974, 207).

When the meditator experiences emptiness during meditation, that person realizes that everything is relational. Emptiness in Buddhism is not a mere feeling of being emptied, but the sense that the meditator experiences as he or she devolves into the innermost layer of being. Zen Buddhist scholar Keiji Nishitani writes that the emptiness of sunyata is not an emptiness represented as some "thing" outside of being and other than being. It is not simply an "empty nothing," but rather an absolute emptiness, emptied even of these representations of emptiness. For that reason, it is at bottom one with being, even as being is one with emptiness (Green \& Elliot, 2010). 
The Buddhist concept of emptiness (sunyata) is not a negative concept that denies the world; rather, it is the "absolute emptiness" as the essence of every being (thing). This feeling of emptiness shatters the self-centeredness of the meditator. Finally, the meditator realizes every being (thing) is relational because everything (being) is originated from absolute emptiness. Epstein explains, "If things have no intrinsic or absolute reality, then everything must be relational. If people realize that everything is relational, they begin to have compassion to the others. Emptiness is like a web or matrix that makes one thing dependent on another" (Epstein, 2001, 33). In addition, according to Epstein, the root of the word "sunyata" has the meaning of "womb." Every being in the world is created from the womb. Likewise, emptiness (sunyata) can be interpreted as neither a mere nothingness nor a void but the source of creation.

In the Buddhist meditative practice of Vipassana Meditation, the most important element is that meditators be aware of only the present. In this meditation, one is only aware of any kind of thinking, emotion, sound, or movement of the present moment without any response to them. In other words, the meditator non-judgmentally observes what they are feeling and experiencing in their mind although they might suffer severe discomfort or inner conflict about it. The meditator should be aware of those feelings without resistance or defensiveness: "Buddha asserted that mindfulness-awareness without judgment, attachment, or aversion to what is happening in the present moment was the most important factor in diminishing unwholesome states of mind and cultivating wholesome ones" (Rubin, 1996, 157). Meditators are not without inner conflicts, but they are experiencing those conflicts without any attachment, defensiveness, or aversion to them (Rubin, 1996). This is the aspect of meditation that differs from Freud's psychoanalysis, the aim of which is to expel inner conflicts.

The Buddhist doctrine of non-attachment makes the non-judgmental way of meditative practice possible. During this practice, people try to overcome any attachment to things and other people because attachment creates judgmental reactions to things and to others. It is tempting to interpret non-attachment as an escape from the world (Epstein, 1995, 40). The Buddhist theory of non-attachment indicates, however, that human beings should be liberated from attachments that prevent them from seeing the reality of the world. When human beings have an attachment to something or someone, they objectify it. They do this so that they can be unconscious of the dynamic nature of that person or thing that is constantly changing and moving. Human beings are able to see and accept things or people as they are without judging and distorting reality only after overcoming attachments to those things or people. Schermer writes, "What Buddhist 'non-attachment' is really about is detachment from 'thing-ness' and objectification. To genuinely love another is to perceive him clearly as he is in the moment" (60).

\section{Psychoanalysis}

For Freud, the use of patients' psychological suffering is an important tool for their mental health. If the symptoms of suffering disappear, an analyst might restore the patient's suffering in a different form to cure the suffering. Freud 
insists, "If, owing to the symptoms having been taken apart and having lost their value, his suffering becomes mitigated, we must reinstate it elsewhere in the form of some appreciable privation" $(1909,163)$. Although it might be painful and cruel to impel a patient to face this suffering, it enables the analyst to investigate the unconscious of the patient as a way to ultimately improve the patient's psychological health. Otherwise, the improvements might become "insignificant and transitory ones" $(1909,163)$. The patient should have the courage to perceive the symptoms and find the courage to direct his attention to the phenomena of his illness. His illness itself must no longer seem to him contemptible, but must become an enemy worthy of his mettle, a piece of his personality, which has solid ground for its existence and out of which things of value for his future life can emerge $(1914,152)$. He should not perceive suffering as something to avoid or hate, but to use as an agent toward recovery.

Psychoanalysts emphasize an awareness of the present during analytic sessions. Freud writes, "[the analyst] contents himself with studying whatever is present for the time being on the surface of the patient's mind" $(1914,147)$. An analyst should regard the illness of the patients as a present force, "not as an event of the past" (1914, 151). Freud (1912) introduces this way of "evenly hovering attention" to conduct a better analysis of the patient's condition. Accordingly, an analyst and his patient should not concentrate on only one thing. Because of a patient's "inclinations" in selecting what he is experiencing in his mind, "there is the danger of never finding anything but what is already known" $(1914,152)$.

For Freud, the basic technique of psychoanalysis is a non-judgmental analysis of a patient's condition, paralleling the non-judgment of the meditation practice. Freud repeatedly admonishes psychoanalysts to "suspend...judgment and give...impartial attention to everything there is to observe" $(1909,23)$. Psychoanalysts should develop their ability to listen to patients without forming any judgments as a way to investigate the patient's unconscious $(1912,111-112)$. In this non-judgmental method of "evenly-hovering attention," analysts should avoid "mental activity, memory and desire" (Bion, 1970, 42). Analysts should have the ability to "forget, the ability to eschew desire and understanding" (55) and "[eliminate] criticism" (Freud, 1909 , 101). Kohut's recommendation to analyze patients in an empathetic way is not much different from Freud's "evenly-hovering attention." Kohut declared Freud to be one of the "par excellence pioneers in the scientific use of introspection and empathy" (Kohut, 1959, 464). Because Freud's method of analysis in exploring the unconscious is non-judgmental, Freudian analysis might be considered empathetic.

As mentioned previously, for Kohut, there is no clear distinction between subject and object. He invented the concept of self-object to explain this close relationship between subject and object as he overcomes the dichotomy between them. The empathy Kohut recommends to analysts also needs to be understood in the context of the concept of self-object. That is, the curing of a patient takes place when the patient feels and sees the analyst as a self-object that participates and resides within the psyche of the patient's world: "The gradual acquisition of empathetic contact with mature self-objects is the essence of the psychoanalytic cure" (Kohut, 1984, 66). Analysts should also acknowledge that they must comfort and soothe patients' needs (Kohut, 1959, 476). 
Kohut introduces empathy as one of the most important tools for dealing with patients. According to Kohut, empathy is a "value-neutral mode of observation: a mode of observation attuned to the inner life of man" (Kohut, 1981, 84). Freud's method might have been a precursor to the empathetic method for therapy because of his "value-neutral" approach to the patient. However, since the starting point of his analysis was a Cartesian view, which separates the subject as the analyst from the object as the patient, he could not develop a mature empathetic method, by which the analyst does not exist outside the patient, but resides as part of the self of the patient.

Consequently, Freud's approach, despite its potential to be an empathetic one, neglects the importance of empathy in the clinical setting. Without the empathetic method, analysts may see the behaviors of patients as mere responses to stimuli, just as the natural scientist observes "cause and effect" in things that exist outside themselves. Kohut writes, "If there is conscious or unconscious intent with which we can empathize, we speak of a psychological act; if no such intent is present, we think of a cause-and-effect chain of physical events" (462). The psychological phenomenon of a patient becomes "somatic, behavioristic, or social" if the observations of the analyst do not include "introspection" and "empathy" $(1959,462)$. The empathetic method is a relational one that does not separate subject from object.

According to Kohut, it is necessary to satisfy a patient's desires, such as the desire to be soothed and comforted during therapy time. In contrast to Freud's view that an analyst must avoid satisfying a patient's narcissistic desire or transference, Kohut insists that even narcissistic desire and transference can be transformed to develop into a mature self-object, which finally creates the mental health of the patient.

However, an analyst should not fully satisfy the narcissistic needs of the patient; the patient must feel "optimal frustration." Kohut discovered the importance of this "optimal frustration" when he observed the psychological development of an infant. An infant needs self-objects that lead him to be optimally frustrated for his psychological development: "The infant needs self-objects who are capable of providing an empathetic environment that is 'optimally frustrating' while simultaneously not damaging to the infant's self”' (Kohut, 1971, 58).

Kohut applies this function of "optimal frustration" to a clinical situation. The self-object functions to enhance the self-hood of the patient. Kohut's empathy toward patients is not the same as the gratification of the patients' desires. Although the analyst should be empathetic to the patient, the analyst is responsible for the patient's understanding of what is currently taking place in his or her current relationship with the analyst. The analyst should let the patient see the reality of his or her own condition by introducing the analytic interpretation of the present relationship between the analyst and the patient. In this way, the patient begins to establish his healthy internal structure by internalizing the analyst as a self-object.

\section{Comparison Between Buddhism and Psychoanalysis}

From the Zen Buddhist perspective, the certainty of the individual self is an illusion. In contrast to modern Cartesian philosophy's view of individual self-certainty, Buddhism examines and denies any self-certainty as well as any existence of objects that 
surround the self. Buddhism arrives at the conclusion that there is no subject that is separated from the object. Similar to this, Kohut proposes that self cannot be separated from object, as he explains the concept of self-object.

For Kohut, however, there still exists the distinction between self and object. Although it is not a clear separation, it exists nevertheless because of the nature of self that is at "once connected" yet "separated," as mentioned above. Likewise, Kohut does not completely overcome Cartesian philosophy because he recognizes the existence of self which is independent of others. In contrast, Buddhism overcomes the dualism with "the spirit of inquiries," which doubts and negates self as well as object. Self as inquiring spirit is no longer a separate entity, but becomes the means to experience the non-dualistic world as its own essence. As one Zen patriarch states, "O my good and intelligent brethren, the Self-essence embraces all things, and on that account it is called great. All things exist in the Essence of every sentient being" (Suzuki, 1952, 31). According to Kohut, the individual "cohesive self" or "nuclear self" still exists. For Buddhists, this is the illusion of self because "self" has a tendency to "confuse being fulfilled with being something" (Martino, 146). In other words, self tends to objectify and regard itself as something immutable. Suzuki (1952) writes, "Scientific knowledge of the self is not real knowledge as long as it objectifies the self" (25). Although Kohut tries to overcome the objectivity of self by creating the concept of self-object, he still objectifies the self in some aspects with his supposition of the existence of "cohesive self" or "nuclear self." Compared to Kohut's concept of self, there is no consistent and coherent self in Zen Buddhism. Buddha said, "a wrong view arises in him as follows: This, my Self, which speaks and feels, which experiences the fruits of good and bad actions now here and now there, this Self is permanent, stable, everlasting, unchanging, remaining the same for ever and ever" (Majjhima Nikaya, 2, 8).

On the other hand, Zen Buddhism's emphasis on "the spirit of inquiries" that doubts and denies the existence of self may lead to a danger of neglecting the importance of identity formation in human development. In psychoanalytic objection-theory, the deepest psychopathological problem is that a patient does not have a cohesive self (Engler, 23). The anatta (no-self) doctrine might be used to rationalize the psycho-pathological problem. Engler, a Buddhist psychoanalyst, points out the danger of "no-self" doctrine for people who have Borderline Personality Disorder.

If "self" does not exist, then basic existential questions of human beings such as "Who am I? or "Who are you?" are meaningless. People may believe that Buddhists do not need to bother to ask questions about their own identity because there is no self according to Buddhist doctrines. If there is neither the self who questions nor the self that answers the questions, then Zen practice such as Koan, where Zen masters asks paradoxical questions to Zen students, would be pointless. This is one of the common misunderstandings of Buddhism.

Zen Buddhism's strong skepticism about self, however, needs to be understood from the developmental perspective. Engler insists that Buddhists' no-self doctrines presuppose even a cohesive and integrated self: “...it is developmentally necessary to acquire a cohesive and integrated self first, one that is differentiated from others and has a degree of autonomy" (Engler, 39). Without a developmental understanding of Buddhism, it is easy for the people with Borderline Personality Disorder to 
misinterpret the meaning of "no-self." Human beings should establish the sense of self-hood in order to experience "no-self" in Buddhist meditation. In a sense, Buddhists' no-self doctrine is a way of achieving a seamless and cohesive self for psychological health.

Moreover, the middle way (neither the self nor the no-self doctrine) in Buddhism may be interpreted in terms of Donald Winnicott's the theory of "transitional object." According to Winnicott, the transitional object is neither "inside the individual nor outside in the world of shared reality" (Winnicott, 1971, 110). The transitional object is experienced in the "intermediate area" between one's inner mental world and the outside, physical world. In Zen Buddhism, the "I" that doubts everything about self is neither "not-me" nor "me." This "I" is experienced as a "transitional phenomenon" in Zen practice. Epstein writes, "[meditation] is transitional to something new: a state in which the reality of the separate self is called into question" (Epstein, 124).

\section{Mental Problems and Healing: Limits and Possibilities}

Buddhism introduces a meditation practice where people are mindful of their mental conflict of the present. This meditation practice is reminiscent of Freud's "evenly hovering attention." Through "evenly hovering attention," Freud focuses on the importance of the awareness of the symptoms of suffering during a therapeutic session. The meditator's awareness of the present moment can also be interpreted as Winnicott's (1971) "transitional phenomenon," where "meditators hear a loud sound with bare attention, for example, they do not distinguish the hearer from the sound. Instead, there is only the moment of hearing, the coming together of internal and external" (Epstein, 123).

However, while Freud's "evenly hovering attention" to the present reenacts past traumatic experiences, Vipassana meditation does not necessarily or intentionally return to the past. The meditation works as long as the meditators are aware of what is happening now, within and without themselves. In this context, meditation as a therapeutic method is close to Kohut's approach to the patient's past. According to Kohut, it is impossible to revive past traumatic experiences, since they were already transformed and exist in a different structure from the present: "They cannot be revived because the developing self had turned away from them early in life, since it was able to shift to different sources of structure formation" (Kohut, 1984, 44).

For Freud, the basic technique of psychoanalysis in analyzing patients' conditions is non-judgmental, just as the method of mediation is non-judgmental. Although Freud addresses the importance of "evenly hovering listening" and "free association" as nonjudgmental methods for understanding of the condition of the patient, he is not quite successful in explaining how a non-judgmental method is possible. Freud merely suggests a comfortable posture and relaxed atmosphere for this purpose. It is extremely difficult to take non-judgmental views about oneself and others because there exists a power relationship between oneself and others. In this power relationship, one unconsciously tends to judge others, be judged by others, and criticize oneself. From the Buddhist perspective, because of attachment between oneself and others, power 
relationships can function between them. As a result, in order to overcome the power relationship so that a non-judgmental awareness is possible, one must first find one's own attachment and overcome it. In this context, the Buddhist practice of "non-attachment" doctrine makes "non-judgmental" awareness possible.

On the other hand, Kohut's "empathy" as a therapeutic method is closely related to his non-Cartesian understanding of the relation between subject and object. In a similar way, Buddhism's compassion can be understood in terms of the concept of "emptiness" that emphasizes the interconnectedness between subject and object. Just as Winnicott (1971) regards a "good enough mother" as a source to develop an infant's mental capacity, in the meditative mood, the meditator's experience of emptiness as a psychological womb leads to a person's mental well-being.

The meditator makes efforts to discover his or her own hidden desire for self-certainty. In contrast to Kohut, who encourages some satisfaction of narcissistic desires of self, in Buddhism, any attempt to satisfy the desire of the self creates suffering. Although Kohut regards the formation of a cohesive self to be important for mental health, in meditation, the formation of a cohesive self does not solve the problem of self; rather, the attempt to form the self creates suffering. Furthermore, Engler points out, "...[in meditation], the striving for sense gratification and for selfhood, which have been the basis of mental life up to and including the stages of identity and object constancy, are seen as the next potential point of arrest and source of suffering" (Engler, 44). In this context, Buddhism is close to Freud's psychoanalysis, which prohibits any gratification of the patient. In Buddhism, however, to know self is to know what self wants or desires. In order to give up self and experience non-self, self should be first discovered by finding the needs and desires of self. Therefore, Buddhism does not ask meditators to prohibit or suppress gratification; rather, it recommends meditators carefully observe any of their own desires that come from self during meditation so that they are finally able to deconstruct those desires and self-hood can be formed by them.

In Buddhism, the way to solve a problem about self is to discover people's endeavors to form self-certainty and deconstruct them: "[The Buddhist way] did not involve exploration of the sexual and aggressive instincts per se, as Freud suggested, but instead involved the uncovering the instinct for self-certainty" (Epstein, 2001, 134). For Freud, exploring and discovering patients' sexual and aggressive instincts is one way to heal a patient. In Buddhism, meditatively exploring the human's innermost desire for self-certainty and identity is the most important way to overcome suffering. As a result, there is only attachment to be observed and analyzed in Buddhist meditation. It is futile to try to discover a "cohesive self" as the true self. Winnicott also addresses the difficulty of finding a true self. He insists that discovering a false self leads to the discovery of a true self: "There is but little point in formulating a True Self except for the purpose of trying to understand the False Self" (Winnicott, 1965, 148).

\section{Conclusion}

It is difficult to deny the fact that there exists a conceptual gap between analytic and Buddhist language, although I have attempted to show connections between Buddhism and psychoanalysis. The language in Buddhism was developed in the 
context in which Buddha found the ultimate truth of human life and suffering. In contrast, analytic language was developed in the context where analysts dealt with the psychological phenomena which their patients faced. Different situations created different meanings in different languages because "meaning is contextdependent" (2000, Wilber, 167). Therefore, the world that Buddhist language creates must be conceptually different from the world that analytic language creates. Ken Wilber writes, "Language did not merely report the world, represent the world, describe the world. Rather, language creates worlds" (164). For example, it is difficult to understand the Buddhist doctrines of "no-self" and "emptiness" without considering the context in which the doctrines were created. The "noself" doctrine that expresses the reality of a human being that Buddha discovered could be understood by considering the context in which Buddha struggled to solve the ultimate questions he had faced throughout his life. It is extremely difficult to interpret those doctrines in analytic terms that were invented in the clinical situation, in which they were applied to solve the specific problem of a particular patient.

In spite of this conceptual gap, I believe that a dialog between these two areas is still possible because of their common existential situation. The situation where Buddhist concepts were created is not different from that of analysis as we explore the existential situation human beings face. Whether they seek comfort through Buddhism or analysis, all human beings face the same existential situation where forces of both life and death threaten human "finitude" and they want to transcend their "finitude."(Gearing \& Alonzo, 2018) As Tillich writes, "Being is essentially threatened with disruption and self-destruction" (202). As a result, there must exist an existential commonality between both practices because of their common existential situations. That commonality is the basis that makes the dialog possible.

Finally, I believe that both Buddhism and psychoanalysis can be enriched by the dialog between them in spite of the conceptual gap in practice. As I have indicated above, I hope Buddhists will realize the danger of their method for people who have not yet established their own identity. Analytic insight would be beneficial for such individuals. On the other hand, an analyst could delve more deeply into the human mind beyond any kind of self-notions by exploring "no-self" as the nature of self. The COVID-19 era has accelerated the development of future virtual technology as well as a non-face-to-face society. It is expected that this more virtual society will eventually raise the need to renew our understanding of ourselves.

Acknowledgements In this article, I discuss the dialog between psychoanalysis and Buddhism for healing, focusing on the subject of self in both traditions. Recognizing that both traditions are exploring the "self," this article reveals that there are compatible similarities in the recovery of fragmented self and the achievement of anatta (no-self) in an effort to escape from suffering, despite some fundamental differences that are analytical or ideological. I confirm that this work is original and has neither been published nor is currently under consideration for publication elsewhere.

Funding None.

\section{Declarations}

Conflict of interest The authors declare that they have no conflict of interest. 
Human and animal participants All procedures followed were in accordance with the ethical standards of the responsible committee of Seoul Christian University. This article does not contain any studies with human or animal subjects.

\section{References}

Atwood, G., \& Stolorow, R. (1984). Structures of subjectivity. The Analytic Press.

Bion, W. (1970). Attention and interpretation. Basic Books.

Ehrenberg, D. B. (1992). The intimate edge: Extending the reach of psychoanalytic interaction. W W Norton \& Co.

Epstein, M. (1995). Thoughts without a thinker: Psychotherapy from a Buddhist perspective. Basic Books, Inc.

Epstein, M. (2001). Going on being. Broadway Books.

Freud, S. (1909). Analysis of a phobia in a five-year-old boy. In J. Strachey (Ed. \& Trans.), The standard edition of the complete psychological works of Sigmund Freud. Vol. 10. Hogarth Press.

Freud, S. (1912). Recommendations to physicians practicing psycho-analysis. In J. Strachey (Ed. \& Trans.), The standard edition of the complete psychological works of Sigmund Freud. Vol. 12. Hogarth Press.

Freud, S. (1914). Remembering, repeating and working through. In J. Strachey (Ed. \& Trans.), The standard edition of the complete psychological works of Sigmund Freud. Vol. 12. Hogarth Press.

Gearing, R. E., \& Alonzo, D. (2018). Religion and suicide: New findings. Journal of Religion and Health, 57(6), 2478-2499. https://doi.org/10.1007/s10943-018-0629-8

Green, M., \& Elliot, M. (2010). Religion, health and psychological well-being. Journal of Religion and Health, 49, 149-163.

Guenther, H. V. (1974). Philosophy and psychology in the Abhidharma. Berkeley: Shambhala

Hoffman, I. Z. (1991). Discussion: Toward a social-constructive view of the psychoanalytic situation. Psychoanalytics Dialogues, 1, 74-105

Kohut, H. (1959). Introspection, empathy, and psychoanalysis. Journal of the American Psychoanalytic Association, 7, 459-483.

Kohut, H. (1971). The analysis of the self: a systematic approach to the psychoanalytic treatment of narcissistic personality disorders. International Universities Press.

Kohut, H. (1977). The restoration of the self. International Universities Press.

Kohut, H. (1979). The two analyses of Mr Z. International Journal of Psychoanalysis, 60, 3-27.

Kohut, H. (1981). Introspection, empathy, and the semicircle of mental health. In J. Lichtenberg, M. Bornstein, \& D. Silver. (Eds.), Empathy. Vol. I (pp. 81-100). Analytic Press, 1984.

Kohut, H. (1984). How does analysis cure? A. Goldberg (Ed.). University of Chicago Press.

Kohut, H., and Wolf, E. (1978). The disorders of the self and their treatment-An outline. In A. Morrison, M.D. (Ed.), Essential papers on narcissism (pp. 175-196). New York University Press, 1986.

Mitchell, S. A. (1988). Relational concepts in psychoanalysis: An integration. Harvard University Press.

Rubin J. B. (1996) Psychoanalysis and Buddhism. In Psychotherapy and Buddhism. Issues in the practice of psychology. Springer, Boston, MA. https://doi.org/10.1007/978-1-4899-7280-4_10

Schermer, V. I. (2002). Spirit and psyche: A new paradigm for psychology, psychoanalysis and psychotherapy. Jessica Kingsley Publishers

Stolorow, R. D., \& Atwood, G. E. (1992). Contexts of being: The intersubjective foundations of psychological life. The Analytic Press.

Suzuki, D.T. (1952). Essays in Zen Buddhism. Beacon Press.

Winnicott, D. W. (1965). The maturational process and the facilitating environment. Hogarth.

Winnicott, D. W. (1971). Playing and reality. Routledge.

Publisher's Note Springer Nature remains neutral with regard to jurisdictional claims in published maps and institutional affiliations. 